\title{
Cultivating Responses from Students through Literature Circle
}

\author{
Joanna Bunga Noah \\ Faculty of Education, Universiti Kebangsaan Malaysia, 43600 Bangi Selangor \\ E-mail: joannabnoah@gmail.com
}

Received: October 24, 2017 Accepted: December 20, 2017 Online Published: March 20, 2018

\begin{abstract}
The English literature component has been around in the Malaysian Education system since 2000. However, literature as a subject has always been learned more for transactional purposes rather than for its aesthetic value. Basically, a regurgitation of knowledge from years of learning, poured out in one major examination. In this research, the researcher applies a teaching method, called the literature circle in a classroom to study how it could be an effective way to learning literature beyond the classroom and for completing exam papers. Accompanying the literature circle activity is the writing of personal responses to gauge the students' understanding and views on the literature component being studied. This paper discusses the findings of the study that investigates the effect of literature circle in the students' personal responses and also to examine the students' perception towards literature circle. The findings of this study, obtained via qualitative and quantitative instruments, comprising of observations, interviews, personal responses, and questionnaires, provide insights for educators and other researchers into another dimension of the teaching and learning of literature component.
\end{abstract}

Keywords: literature component, literature circle, personal response, education

\section{Introduction}

The English literature component is not an unfamiliar part of the Malaysian school syllabus. It has been integrated into our education since the year 2000. Out of the five periods allocated for English lessons per week in secondary schools, one of the periods is dedicated to teaching English literature components. Our literature components consist of novels, short stories, and poems from local and international authors, handpicked by the Curriculum Development Center (CDC) for the syllabus.

It started with the English Language Reading Program (ELRP) in 1979 as a transition for the change in the medium of instruction from Bahasa Melayu to English in the education system. The emphasis was on using literary materials to enhance the language proficiency. However, due to the weakness in the structure of ELRP to improve English language among the students, Class Reader Program (CRP) was introduced in 1990 and implemented in 1993 as part of the New Integrated Secondary School Syllabus (KBSM). In the year 1999, the Ministry of Education (MOE) decided a change in the policy; therefore, in 2000 the literature component was introduced to Form 1 and Form 4 students, then in 2001 to Form 2 and Form 5 students and finally in 2002 to Form 3 students. The literature component is also tested in major examinations, Lower Secondary Assessment (PMR), and Malaysian Certificate of Education (SPM). The literature component is aimed to enhance students' proficiency, contribute to personal development and character building, broaden outlook: other cultures, world views and through the literature classes, students are enabled to: give personal response to texts, be aware of how language is used, reflect and draw upon moral lessons and understand and appreciate other cultures (Subramaniam \& Vethami, 2003).

The literature component is aimed at highlighting the intentions to enrich the students' proficiency level in English language via the study of prescribed texts, as well as to contribute to the personal development and character building of the students (Subramaniam, 2003). The reintroduction of literature in the syllabus has been documented in the Malaysia Education Blueprint 2013-2025, whereby it would be a compulsory subject in secondary schools to increase students' exposure to the English language. Paramjit Kaur and Nooraida Mahmor (2014) argued that among the strategies outlined in Shift 2 include the 'upskilling' of English language teachers and expanding the opportunities for more exposure to English via a compulsory English Literature component at the secondary school level. The English 
Literature component is foregrounded in the Blueprint and is given the role of promoting English proficiency (Kaur \& Mahmor, 2014).

Other than English literature as a way to gain English proficiency, English literature is equally important in the development of students' personal growth thus my advocating for literature circle as a teaching method to cultivate personal and reader response from students. As we know, there are many teaching methods to teaching the subject of literature that could elicit different personal responses from students. Personal responses are valuable resources to literature subjects, as it would capture the epitome of the lessons from a student's point of view. A personal response in this context is a writing of a student's response to the literature component. It is to gauge the student's response to ideas within a literary text, such as the theme, characters, or summary of the text. It also allows the student to write personal reaction and opinion towards the text and give an explanation along with it.

\subsection{Research Objectives}

This study aims to see the effect of literature circle on the students' personal responses and also to examine the students' perception towards literature circle. This is important as we want the younger generation to not study literature just because it is part of the syllabus but to study literature in-depth and to be able to apply it in their near future.

\subsection{Research Questions}

In view of the above objectives, this study aims to answer the following research questions:

a) How does the use of literature circle affect the students' personal responses?

b) What are the students' perceptions towards the use of literature circle?

This research aims to examine the personal responses of the students towards literature circle as a teaching method in the teaching and learning of literature components.

\section{Research Methodology}

As the aim of this study is to see the effect of literature circle on the students' personal responses and also to examine the students' perception towards literature circle, it is only fair that a mixed method research in the form of a case study is conducted. A case study is suitable as it allows an in-depth and holistic research by closely examining the data within a specific context (Zainal, 2007). Case study examines real life phenomenon through thorough contextual analysis over a few activities and their relationships. Yin (1984) defines the case study research method "as an empirical inquiry that investigates a contemporary phenomenon within its real life context; when the boundaries between phenomenon and context are not clearly evident; and in which multiple sources of evidence are used." There are a few advantages to case study as a research design. Firstly, the examination of the data is most often conducted within the context of its use (Yin, 1984), that is, within the situation in which the activity takes place (Zaidah, 2007). In this case, the researcher observed the students in class during the literature circle activity. Next, the specified qualitative reports often produced in case studies not only help to explore or describe the data in real life environment, but also help to justify the complexities of real life situations, which may not necessarily be captured through experimental or survey research (Zaidah, 2007). In line with that, this research requires the participants to write a response journal, answer a questionnaire, and also undergo an interview, which would ultimately capture their main thoughts and opinions.

\subsection{Research Site and Participants}

The research was conducted at SMJK Yu Hua Kajang, Selangor. This sub-urban National Type Secondary School in Kajang town has over 3000 pupils with 127 teaching staff and has been serving the community since the 1910s. Purposeful sampling was used in order to obtain my respondents, namely the students. This particular type of sampling was chosen so as to meet the purpose of the research as purposeful sampling selects participants based on a sample of information-rich cases that is studied in depth (Wiersma \& Jurs, 2005).

The particular class chosen for this research was class 2E, the fifth class in Form 2. This class was categorised under the good class range with fairly-proficient English language proficiency. The class consists of 46 students, 24 girls and 22 boys, all coming from a Chinese background. All 46 students participated in the literature circles as part of learning a literature component. All 46 students also answered the questionnaires that were given out. However, only 


\section{International Journal of Research in English Education}

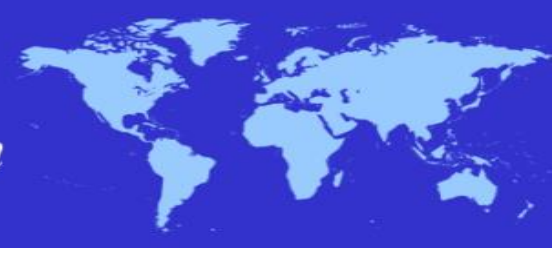

four students were chosen to undergo an interview for this research and they are Alicia Leow Min Li, Pearlynn Khoo I-Yee, Poon Chin San, and Ng Suteng. They were chosen based on their proficiency level and their personal response writings.

\subsection{Research Instruments}

\subsubsection{Observation}

An observation was conducted by the teacher to observe the literature circle activity, in regards to the students' participation and discussion during the activity. This is important as the teacher should be attentive to what is going on during the literature circle and see the students' reaction and participation in it. Other than that, this is a role for the teacher to play as a facilitator of the activity. The observation made by the researcher shall be abiding a checklist, the researcher also made her own notes for her references in writing the next chapters.

\subsubsection{Response Journal}

This research required students to write a response journal after each implementation of the literature circle activity. This would gauge the students' personal thoughts and opinions on the literature component and also their perception towards the teaching method. The writing of the response journal was set around guidelines and writing criteria for the students to follow so they would not deviate from the main idea of the research. Writing a response journal is effective, as it would allow the participants free expression of feelings, thoughts, responses and perceptions without the hindrance and constraints of pre-set question requirements (Mallika \& Jayakaran, 2013). The response journal would also aid the interview as some students might prefer to write down their emotions and thoughts instead of talking it out loud, especially regarding more personal issues. Students are to write their opinions and thoughts based on the few guidelines, once the literature circle activity is completed. Writings are not limited to any word count. Students are encouraged to express themselves as much as possible. The guidelines were given out over three different literature circles.

\subsubsection{Interview}

An interview was also conducted on a few chosen students based on their response journals to elicit more information from them and also to clear up some ambiguous statements that might be made from their response journal. The researcher asked a few questions and then proceeded to transcribing the interviews; each interview was about 5-6 minutes long.

\subsubsection{Questionnaire}

The questionnaire was given out twice, once after the first literature circle (part 1) and the other after the third and last literature circle (part 3). The questionnaire was an attempt to gather a general view from the students regarding some aspects of the literature circle. The responses collected from the students were in a likert scale, measuring from strongly disagree to strongly agree.

\subsection{Data Collection and Analysis Procedure}

The data collection procedure was an on-going process within the duration of 16 weeks. The data collection began with a pre-defined framework, focusing on the aim and objective of the research. This enabled scrutiny on particular answers among the response journal, observation, and interview. Next would be to code the data, to begin with that, the researcher needed to familiarise herself with the data by re-reading the material over and over again. Notes and summaries should be highlighted. Therefore, the data should be coded in order to obtain an interpretation. Through that, themes emerged and various data can be categorised to represent common features thus deductions were made (Anon, 2014).

The researcher observed each literature circle activity and jotted down notes as well, this is to keep a record of how the activity was conducted and the students' involvement in it. The questionnaire was given out twice, once after the first literature circle, named as Part 1 and second after the third and final literature circle, named Part 3. The questionnaire was then analysed and the percentages to the items were calculated and compared. The personal responses were compulsory homework for the students to write after each literature circle. Students had to write it in their literature exercise book and the teacher would collect it the day after. It is important to instruct students to write it immediately after the activity, while the event is still fresh in their mind lest they forget any vital information. Lastly, 


\section{International Journal of Research in English Education}

the interview was conducted to the four chosen respondents after analysing the personal responses and after all the literature circles were over. The researcher prompted the students to give reasons along with their answers to elicit the best response from them. For the next chapter, the researcher has corrected the grammar of the respondents for their interview and personal response quotations.

\section{Findings}

\subsection{The Literature Circle}

The literature circle activity was conducted with Allan Baille's "Cheat" as the anchor story. 6 roles were given to each group of 5-6 students in that particular class. The roles were discussion director, summarizer, word wizard, question writer, the artist and character captain. Students have their own role that changed with each literature circle activity carried out. This was to make sure that the students were able to try out different roles and find which skills suit them the best. The pros of the roles are that the students would be able to learn about the story indirectly from the discussion rather than having the teacher teach them about the story through chalk and talk method. However, due to the rigidity of these roles, the students tend to not go further beyond what is required of them and stop once they have presented their roles. They did not discuss further on the characters and just listened and agreed with whatever the character captain had to say. The discussion director also did not guide them to take the discussion a step further. This was probably due to the education system setting that does not encourage HOTS among the students.

A day before the activity, the teacher gave out the role sheets to each group and the students decided among themselves which role they would like to take on. They then went home to prepare and brought the role sheets back the next day when the literature circle activity took place. Based on the teacher's observation, the first literature circle started out slowly. Students were a little lost at what was expected of them. The teacher, as the facilitator, had to go around and prompt the students to start talking and discussing. For the first attempt, the students just read out their roles and no further discussion about the story took place. However, when the role sheets were returned, a group's discussion director actually had written out a dialogue of the discussion and the dialogue was well written indicating the group knew what they had to do. But once again, no further discussion took place in that dialogue. The second and third literature circle went on better, as students then knew what were required of them. The researcher could also see that teamwork and cooperation were evident among the group members. However, the literature circle discussion did not heighten with Higher Order Thinking Skills (HOTS) and the students stuck to the role sheets guidelines and demonstrated only Lower Order Thinking Skills (LOTS). 


\section{International Journal of Research in English Education}
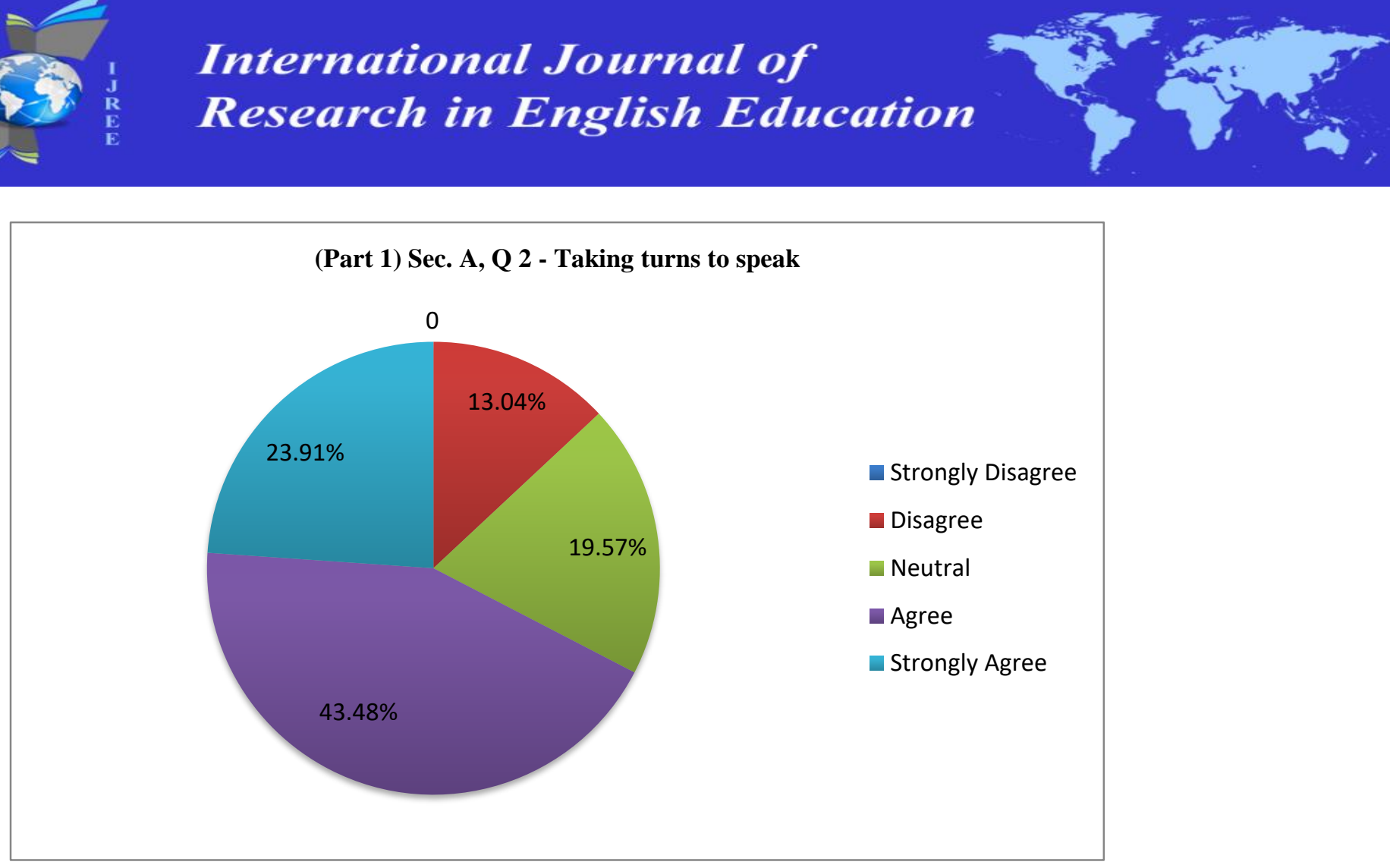

Figure 1. (Part 1) Sec. A, Q.2 - Taking turns to speak

\section{(Part 3) Sec. A, Q 2 - Taking turns to speak}

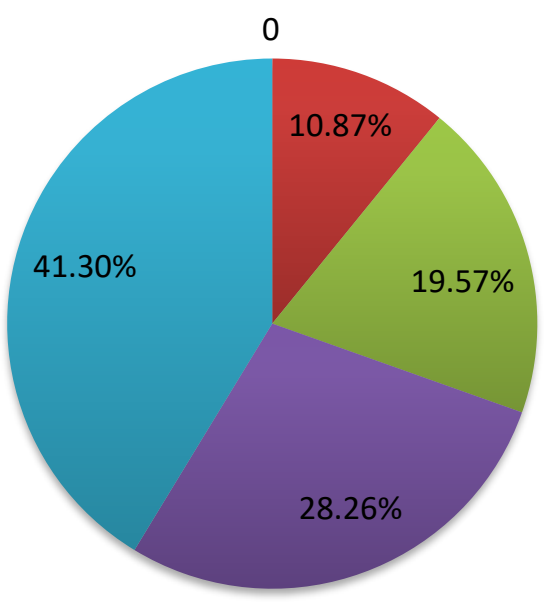

Strongly Disagree

Disagree

Neutral

Agree

- Strongly Agree

Figure 2. (Part 3) Sec. A, Q.2 - Taking turns to speak 


\section{International Journal of Research in English Education}

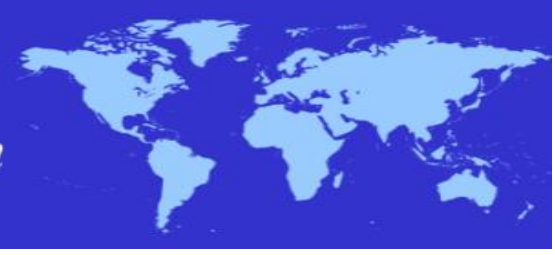

Based on the above graph, we could see that for part 1,67.39\% (see Figure 1) and for part 3,69.56\% (see Figure 2) gave positive feedback to the item "we took turns to speak" thus demonstrating students' participation in the literature circle and their teamwork and cooperation.

Students had good perceptions towards the literature circle as an activity, it helped them to gain further understanding towards the literature component as opposed to the usual chalk and talk method. Other than that, literature circle helps sharpen the 4 skills of reading, writing, listening, and speaking and generates confidence of presenting their ideas to a group.

Last but not least, based on the interview conducted, all four respondents preferred learning literature via literature circle, as it was a fun way of learning and deviated from the usual chalk and talk method. Other than that, it helped them to improve their communication skills, as they had to talk and discuss with their group members. Not to mention, preparing for their roles indirectly helped them revise for their examination. Lastly, they believed that the literature circle was a student-centered activity, which placed more emphasis on their own personal learning. In union with that, Daniels (2002) indicated that literature circles were an excellent way to help students take ownership for their learning.

"I think it's a fun way and helps more in the exam." - Alicia

"It (literature circle) is more interesting and we could communicate to each other...it is more student centered" Pearlynn

"It (literature circle) is easier to understand and learn ... because I have already prepared for the roles and studied on my own" - Suteng

\subsection{The Personal Response}

The students were instructed to write a personal response with guided instructions right after each literature circle. This is as a reflection of what they have learnt and their feelings, thoughts, and opinions on the literature circle. Each personal response had different guided instructions to gauge the students' progress of the activity.

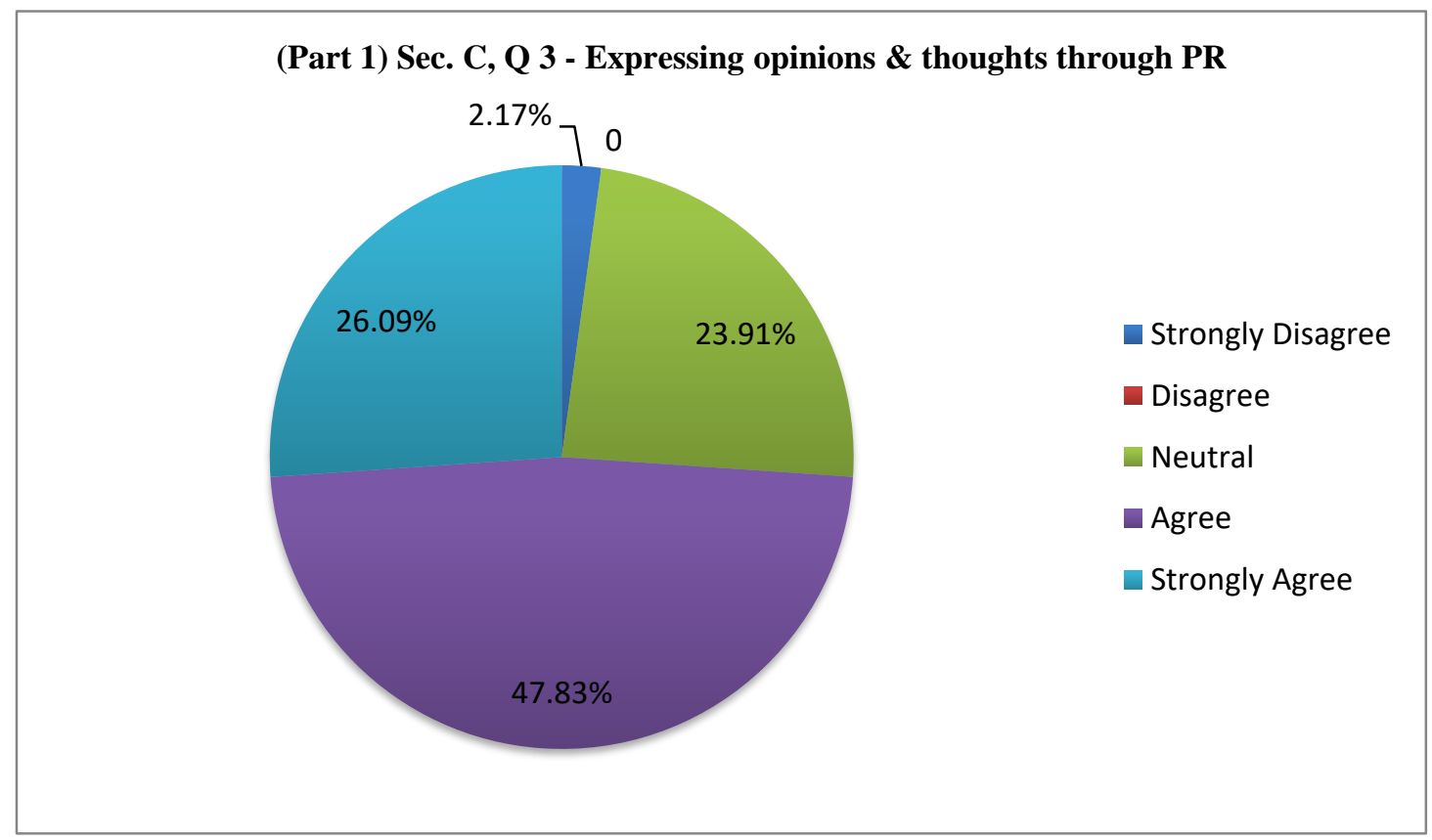

Figure 3. (Part 1) Sec. C, Q.3 - Expressing opinions \& thoughts through PR 


\section{International Journal of Research in English Education}

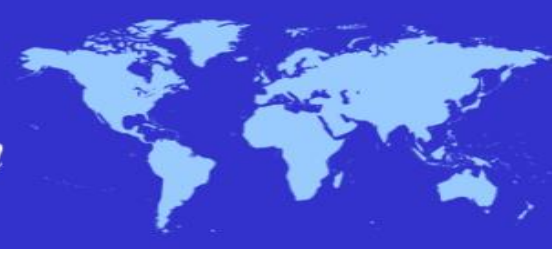

(Part 3) Sec. C, Q 3 - Expressing opinions \& thoughts through PR

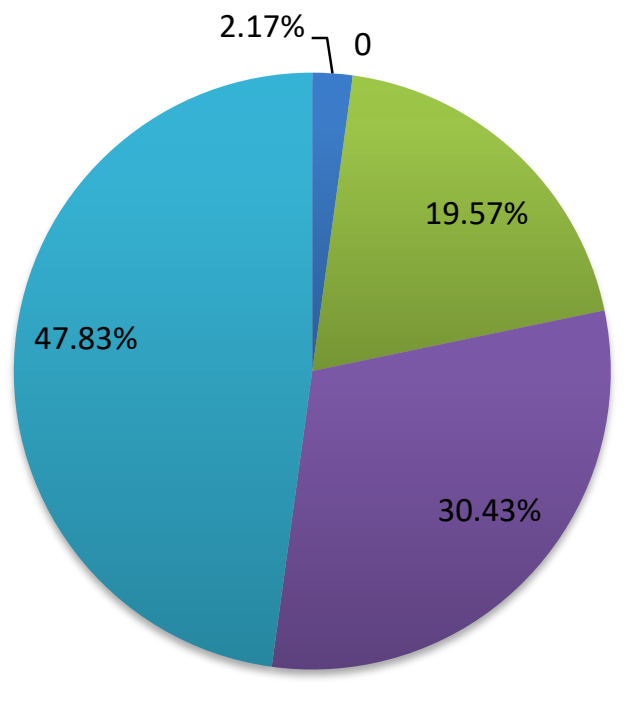

- Strongly Disagree

Disagree

Neutral

Agree

Strongly Agree

Figure 4. (Part 3) Sec. C, Q.3 - Expressing opinions \& thoughts through PR

Based on the questionnaire, item "the personal response enabled me to express my opinions and thoughts without limitation" showed an increase in percentage from part 1 to part 3. For part 1,73.92\% (Figure 3) and part 3, 78.26\% (Figure 4) of students gave positive results respectively. This increase correlates with the effectiveness of the literature circle and their personal response. After three activities, the students have finally gotten the grasp of the personal response and were able to write better.

The first personal response required students to write what they have learnt from the story and the second one required them to write what they had learnt from the discussion. This is a progression between evaluating the text and evaluating their own performance participating in the literature circle. The respondents were honest in sharing their frank opinions and that opened room for them to express their thoughts freely, this interconnects with what has been mentioned above.

For the final personal response, the students managed to tie up the 3 sessions and the 3 parts of the story, giving a very wholesome finale thus finally grasping the essence of the literature circles, which is to develop critical thinking and comprehension skills (Bedee, 2010).

From the analysis above, we can see that the literature circle enabled students to not only read the text on the surface but to also take a minute to evaluate and relate the text to their own personal life thus giving literature another meaning other than just a subject in school.

\section{Discussion}

\subsection{How Does the Use of Literature Circle Affect the Students' Personal Responses?}

The writing of the personal responses was compulsory and the students adhered to the guidelines given. Not many students had written beyond that and although their writings were limitless and free, they were still confined in a way, as they did not write further than the instructions. This shows that students were able to write the personal response well but did not demonstrate any reader response in their writings. Personal response is concerned with reader's response to the author's text (Hirvela, 1996) and reader response is concerned with how the reader's experience and background knowledge would shape the meaning of a text. Thus, we could see that the literature circle facilitated the students to deliver their personal response well but could not give a more in-depth reader response. 
Other than that, the personal response written by the students reflected their focus on the writing skills more than their personal growth. Although the data has some proof of personal growth, the researcher could not see further definite evidence and the students were still focused on answering the guidelines given rather than showcasing their personal growth. Rosenblatt's Transactional Theory (1987) explains the learners' involvement in forming connection between texts and learners and creating their own meaning. A literature circle activity should be able to assist students in establishing their own meaning from the text they have read. This meaning could be translated into the writing of their personal responses. However, as the researcher has read through all 46 responses, only a few were able to display personal connections to the text. One example was from a student who had related that the character's dishonest moment to his own friend cheating in an exam. That showcased the student's ability to connect and reflect the text to his own personal life. But as I mentioned, only a few were able to do so, thus concluding once again that the literature circle conducted at SMJK Yu Hua for class 2E rarely elicited responses beyond students' own meaning.

One way to encourage the students to give their reader response is by still giving guidelines and samples of writing that encourage reader response compared to personal response. The teacher could also orally elicit reader response from the students, give feedback to them and ask them to jot it down in their writings.

\subsection{What Are the Students' Perceptions towards the Use of Literature Circle?}

The literature circle activity aims to create a platform for the students to be able to learn literature through a collaborative learning with their classmates instead of the usual chalk and talk teaching method. The literature circle promotes HOTS, team cooperation and it should be able to sharpen the students' English language proficiency. The following discussion touches on the various aspects of the literature circle and what was found during the research based on the data analysis.

\subsubsection{Higher Order Thinking Skills (HOTS)}

Literature circle is basically a discussion on a particular literature component. Consequently, from discussing the surface of the story, like the characters or the summary, the students should be able to steer their discussion into a deeper one by questioning certain aspects of the story whereby the answers cannot be found in the story itself. This is HOTS and would trigger critical, creative, and analytical thinking skills among the students. However, from the observations we could see that HOTS were not incorporated into the literature circles. This could be due to many factors, first would be that the students themselves are not familiar to HOTS without prompting. Thus, they limit themselves to the task/instructions given, in this case the role sheets without going further as they do not know how to initiate further discussion. Other than that, the teacher as a facilitator also plays a huge role in supporting the students to move into HOTS for their discussion.

\subsubsection{Team Cooperation}

The students believed that there was a strong presence of teamwork in the discussions. The respondents defined teamwork as each member being able to contribute to the discussion. Contribution here is defined as each member being able to complete their homework/role sheet and share it with the group. However, the researcher feels that teamwork should not only stop at that, but team cooperation in the discussion could be heightened when they would go into further discussion. This correlates with the HOTS discussion above. As of now, the discussion is merely a presentation of their roles and barely a lively discussion.

\subsubsection{English Language Proficiency}

Based on Carter and Long (1991), The Language Model should enable the students to use literature as a platform to increase language proficiency, as it is an integration between language and literature in the classroom. A group discussion is conducted orally thus in an English class, a discussion is the best platform to hone your language skills and improve your second language proficiency. Based on analysis, as the students are all Chinese, they tend to discuss in Mandarin unless the teacher was facilitating their group. This was not due to their proficient level but their comfort level of speaking in Mandarin to their peers. In short, the literature circle did not further sharpen their English language speaking skills. From here, we can see that The Language Model was not apparent in this classroom.

It is clear that the literature circle had helped the students to further comprehend the text, taught them about teamwork and most importantly for them to step out of their comfort zone and learn something new, as the dynamics of the discussion had incorporated various roles that allowed them room to interact with their teammates in order to 
understand the story. This method of teaching literature promotes self-learning, as they are not depending on the teacher to explain the story to them but they need to discuss with their members to achieve understanding of the text. Lastly, the students had a good perception towards the literature circle but there was definitely room for improvement when conducting literature circle as a teaching method.

\section{Implications}

For the implications of this research, the researcher strongly believes that literature circle should be a mandatory element of the syllabus in teaching and learning as proven, it can bring out many dimensions to the learning of literature and definitely helps the students to see the subject beyond their classroom walls. While this study concentrates on conducting the literature circle and writing of personal response, future researchers could delve deeper into the technical aspects of the literature circle and the various types of personal responses that could also aid the students in learning of the literature components and for various proficiency levels. It is hoped that the findings of this study will give educators and other researchers insight into another dimension of the literature component.

\section{Conclusion}

Literature circle as a teaching method had worked amazingly and could be further developed and was well suited for the students' level but literature was treated more as a regurgitation of knowledge and was learnt for transactional purpose rather than the aesthetics of it. The researcher conducted the literature circle with the hope that changes could be turned, but the students were still not supportive towards the change. It is undeniable that the way literature has been taught in Malaysia's education system should change in order for students to come out of this cocoon. However, growth is not tangible and should not be measured by their performance during the literature circle or the writing of the personal response, but hope to be of use in their future.

In conclusion, literature circle is another teaching method to teaching literature in secondary schools. Literature circle gives a holistic learning environment, as it not only incorporates many skills but perfects students' HOTS, teamwork, and language proficiency too. Teachers need to be able to assess their students' level of understanding and proficiency before they can proceed with the literature circle, in terms of guidelines for roles and writing of personal response. Literature circle is also proven to help students with their reading, listening, speaking, and writing skills thus this activity enables the students to be developed holistically. Not to mention, the literature circle enables the literature components to create a collaborative learning process among the peers, in line with Malaysia's 21 st Century Learning vision. Last but not least, as literature circle sharpens their English language usage, ultimately students are able to learn something new and self-evaluate their own learning curve.

\section{References}

Anon. (2014). 6 Methods of data collection and analysis. www.open.edu/openlearncreate/mod/resource/view.php?id=52658 [13 December 2016].

Bedee, S. (2010). The impact of literature circles on reading motivation and comprehension for students in a second grade classroom. Master Thesis, Bowling Green State University.

Carter, R., \& Long, M. (1991). Teaching literature. London: Longman.

Curriculum Planning \& Development Divison Ministry of Education. (2013). Literature in English Teaching Syllabus 2013 Lower and UpperSecondary.

Daniels, H. (2002). Literature circles: Voice and choice in book clubs and reading groups. Markham, ONT: Stenhouse Publishers.

Govindarajoo, M. V., \& Mukundan, J. (2013). Young adult literature in the Malaysian secondary school. English Language Teaching, 6(11), 77-88. doi:10.5539/elt.v6n11p77 URL: http://dx.doi.org/10.5539/elt.v6n11p77

Hirvela, A. (1996). Reader-response theory and ELT. ELT Journal, 50(2), 127-134. Oxford: Oxford University Press.

Kaur, P., \& Mahmor, N. (2014). Examining the role of the English literature component in the Malaysian English curriculum. Procedia-Social and Behavioral Sciences, 134 (September 2012), 119-124.

Malaysian Examinations Council. (2013). Literature in English.

Ministry of Education Malaysia. (2013). Malaysian Education Blueprint, 2013-2025. 


\section{International Journal of Research in English Education}

Ramlan, N. (2009). Teachers' preferred practices in teaching literature component in Kuching-Samarahan divisions secondary schools. Project Report (B. Sc.), Universiti Malaysia Sarawak.

Rosenblatt, L. M. (1978). The reader, the text, the poem: The transactional theory of the literary work. Carbondale: Southern Illinois University Press.

Subramaniam, G., \& Vethami, M. E. (2003). Teaching of literature in ESL/EFL contexts. Petaling Jaya: Sasbadi.

Wiersma, W., \& Jurs, S. G. (2005). Research methods in Education: An introduction. London: Pearson.

Yin, R. K. (1984). Case study research: Design and methods. Beverly Hills, Calif: Sage Publications.

Zaidah, Z. (2007). Case study as a research method. Jurnal Kemanusiaan, 9, 1-6.

Zainal, Z. (2007). Case study as a research method. Jurnal Kemanusiaan, 9, 1-6. http://eprints.utm.my/8221/4/48case-study-as-a-research method.html_Itemid\%3D1328 [15 December 2016]. 